\title{
Development of the Rat Superior Cervical Ganglion: Initial Stages of Synapse Formation ${ }^{1}$
}

\author{
ERIC RUBIN ${ }^{2}$ \\ Department of Physiology and Biophysics, Washington University School of Medicine, St. Louis, Missouri 63110
}

\begin{abstract}
Synapse formation in the rat superior cervical ganglion has been investigated electrophysiologically and at the ultrastructural level. Preganglionic axons first enter the superior cervical ganglion between days 12 and 13 of gestation (E12 to $E 13)$, and on $E 13$ a postganglionic response can be evoked by preganglionic stimulation. The susceptibility of this response to fatigue and to blocking agents indicates that it is mediated by cholinergic synapses. On E14, the overall strength of ganglionic innervation arising from different spinal segments already varies in a pattern resembling that found in maturity. However, the distribution of synapses on individual target cells gradually changes in the prenatal period. Transmission begins prior to the elaboration of ganglion cell dendrites; therefore, the first contacts to form are largely axosomatic. As dendrites appear (beginning on E14), ultrastructural evidence shows that synaptogenesis becomes focused upon these processes. The significance of these findings is discussed in relation to possible mechanisms for the formation of appropriate synaptic connections.
\end{abstract}

The preceding papers (Rubin, 1985a, b) describe the maturation of principal neurons in the rat superior cervical ganglion and the outgrowth of axons from the spinal cord to the ganglion cells. The culmination of these events is the formation of ganglionic synapses. Synaptogenesis in the sympathetic system is of particular interest because the connections found in maturity are highly patterned (Njå and Purves, 1977a; Lichtman et al., 1979). In rodents, considerable synaptic organization is already evident at birth; by this time the overall innervation pattern of the superior cervical ganglion is established, although the innervation of individual target cells is still in the midst of substantial rearrangement (Lichtman and Purves, 1980). The present work examines the stages of synapse development that give rise to the pattern of connections found at birth. Physiological and ultrastructural techniques have been used to study the onset of synaptogenesis in the rat superior cervical ganglion, and to trace

Received April 23, 1984; Revised August 17, 1984;

Accepted August 22, 1984

${ }^{1}$ I thank Dale Purves for his support and advice throughout this study. and C. J. Forehand and R. D. Hadley for comments on the manuscript. Expert technical help was provided by Emily Gordon, Pat Newton, and Dorothy Dill. Thanks also to Sue Eads and Jan Wuelling for typing the manuscript, and to Vicki Friedman for help with illustrations. This work was supported by grants from the National Institutes of Health (NS-11699 and NS.18629), and from the Muscular Dystrophy Association to D. Purves.

${ }^{2}$ To whom requests for reprints should be sent, in care of Dr. D. Purves, at Department of Physiology and Biophysics, Washington Universily School of Medicine, St. Louis, MO 63110. some aspects of synaptic organization through the prenatal period. Some of these results have been briefly reported (Rubin, 1982).

\section{Materials and Methods}

The procedures for obtaining and isolating fetal rats have been described (Rubin 1985a, b). As in the previous papers, the day of conception is counted as embryonic day zero (E0), and the first postnatal day is termed P0.

Flectrophysiology. In isolated fetuses, the right superior cervical ganglion was exposed, along with the internal carotid nerve and the cervical sympathetic trunk (see Rubin, 1985a). The dissection was carried out at room tempcrature in a standard Ringcr's solution $(\mathrm{pH} \mathrm{7.2)}$ of the following composition (in millimolar concentration): $\mathrm{NaCl}, 137.0 ; \mathrm{KCl}, 4.0 ; \mathrm{MgCl}_{2}, 1.0$; $\mathrm{KH}_{2} \mathrm{PO}_{4}, 1.0 ; \mathrm{NaHCO}_{3}, 12.0 ; \mathrm{CaCl}_{2}, 5.0 ; \mathrm{D}$-glucose, 11.0, gassed with $95 \%$ $\mathrm{O}_{2}, 5 \% \mathrm{CO}_{2}$. Preparations from $\mathrm{E} 13$ or older were used; prior to this age the ganglion is difficult to isolate for electrophysiological recordings. Using tissue around the ganglion, the preparation was pinned onto a platform of Sylgard resin and transferred to a bath continually perfused with oxygenated Ringer's solution at room temperature. The bathing fluid could be switched from the standard composition to either a high $\mathrm{Mg}^{2+}(8.0 \mathrm{~mm}) / \mathrm{low} \mathrm{Ca} \mathrm{Ca}^{2+}(0.5 \mathrm{~mm})$ Ringer's solution (with $\mathrm{NaCl}$ altered to match the tonicity of the standard solution), or to a solution of D-tubocurare $(0.12 \mathrm{mg} / \mathrm{ml})$ in standard Ringer's solution. For preganglionic stimulation, either a suction electrode or a small bipolar electrode (made of Teflon-coated wires $100 \mu \mathrm{m}$ in diameter, exposed only at their tips) was placed on the cervical sympathetic trunk. A suction electrode on the internal carotid nerve was used to record postganglionic compound action potentials. Suction electrode tips were made from micropipettes broken to a suitable diameter and fire polished. On E13, the cervical sympathetic trunk is not yet distinct (Rubin, 1985b); therefore, the caudal portion of the stellate ganglion was drawn up and stimulated. The internal carotid nerve also is rudimentary on E13; thus, the recording electrode necessarily contacted the surface of the ganglion around the base of the nerve. Nonetheless, recordings obtained in this way corresponded to recordings made later in gestation when electrodes could be better positioned on pre- and postganglionic nerves. Electrical stimulation was delivered in 0.5 msec pulses of up to $70 \mathrm{~V}$. Compound action potentials were led through an AC-coupled differential amplifier for display. The amplitude of a potential recorded under these conditions is influenced by circumstances such as electrode positioning and the effectiveness of the electrical seal on the postganglionic nerve. Especially with fetal ganglia, these variables were difficult to reproduce between experiments; therefore, developmental comparisons have not been drawn on the basis of absolute amplitude.

In some experiments the preganglionic supply to the superior cervical ganglion was stimulated through individual ventral roots. After exposing the ganglion, the rib cage was pinned to a Sylgard base and the spinal cord was exposed dorsally. The dorsal root ganglia were freed of surrounding tissue, and, in neonatal animals, the spinal cord was removed to leave sufficient lengths of ventral root within the spinal canal for stimulation with a bipolar electrode (see above). On E14, the spinal cord was left in place and the bipolar electrode was inserted obliquely between dorsal roots to contact ventral roots. In this way, individual ventral roots were stimulated while monitoring the internal carotid nerve, as described above; care was taken to hold the recording electrode in the same position as successive roots were tested. Controls were carried out in which the bipolar stimulating electrode was moved dorsally away from a ventral root the same distance as would be covered moving longitudinally to the neighboring root. Such movement abolished postganglionic responses at the stimulus strengths used, indicating that current spread was unlikely to cause inadvertent stimulation of ventral 

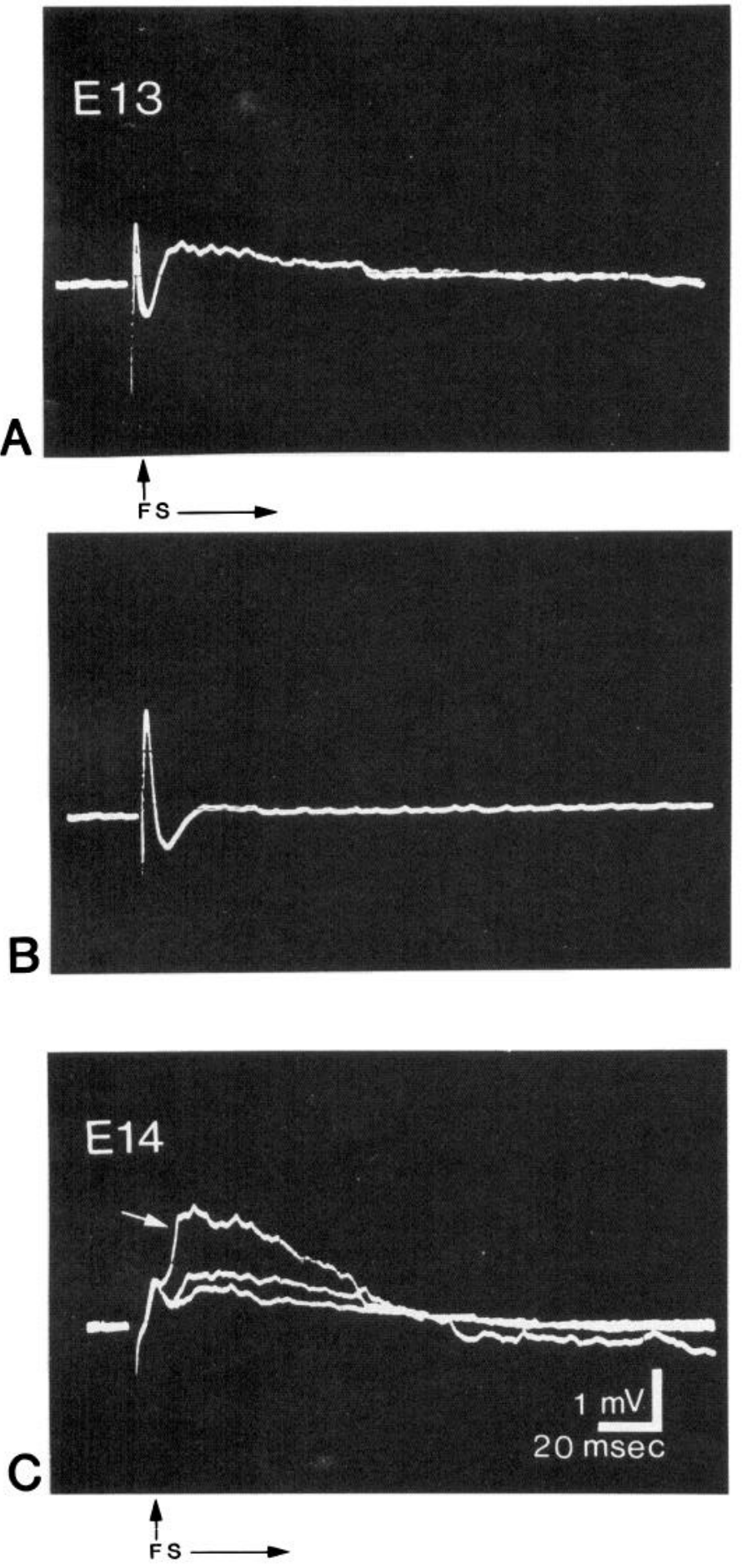

Figure 1. Responses recorded on E13 and E14 from the superior cervical ganglion. Preganglionic stimulation on E13 was delivered by drawing the stellate ganglion into a suction electrode (see "Materials and Methods"). The recording electrode was on the internal carotid nerve. $A$, Response after a single suprathreshold shock on E13. The fast component of the response $(F)$ is partially obscured by the stimulus artifact. The slow component $(S)$ is irregular and of long duration. $B$. The response of the same $E 13$ ganglion to the last shock in a series of three at $1 / \mathrm{sec}$; same stimulus intensity as in $A$ Repetitive stimulation markedly depresses the slow wave but not the fast wave. The fast wave appears larger than in $A$ due to repositioning of the recording electrode. After 5 min of rest, the slow response recovers fully (not shown). C, E14 response to a series of three shocks at $1 / \mathrm{sec}$; successive traces are superimposed. The white arrow points to the slow response following the first shock; on E14 the slow wave is more prominent relative to the fast wave than on E13. With repetitive stimulation, the slow wave roots adjacent to the one being studied. In all cases, the integrity of ventral roots was monitored by observing contractions in the corresponding intercostal muscle during stimulation. The ability to selectively activate a single segment's muscle confirmed the precision of the stimulus (cf. Dennis et al. 1981).

Electron microscopy. Superior cervical ganglia were fixed in situ by immersion in a mixture of aldehydes, including acrolein (for details, see Rubin, 1985a). Thin sections were generally examined from the middle portion of the ganglion, and synapses were counted from photographic montages made at a primary magnification of $\times 8000$. These montages were made as strips that spanned the cross-section of the ganglion; thus, a representative range of territories was sampled, including regions of both high and low cell density and neuropil density. Synaptic contacts were identified by the presence of vesicle-containing profiles accompanied by dense membrane specializations. To compensate for changes in cell size or extracellular space during development, counts of synapses were normalized to the number of complete nuclear profiles (equated to the number of cell perimeters) encompassed during the counting procedure. Glial proliferation occurs relatively late in the rat superior cervical ganglion, so that most cells seen before birth are likely to be neuronal (see Rubin, 1985a). However, if some of the cells scanned during synapse counts were non-neuronal, the observed number of synaptic contacts per cell perimeter would tend to underestimate the number of contacts per neuronal perimeter.

\section{Results}

The onset of synaptic transmission. The cervical sympathetic system is first distinct on E12 (Rubin, 1985a); before E13, however, it cannot be surgically isolated. By E13 a small number of preganglionic axons have grown through the thoracic sympathetic chain into the rudimentary superior cervical ganglion (Rubin, 1985b). These axons could be stimulated in the thoracic chain at the level of the stellate ganglion (see "Materials and Methods").

Single-shock stimulation on E13 evoked a response from the superior cervical ganglion with two components (Fig. 1A): a shortlatency signal with a rapid time course, followed by a more variable signal of longer duration. Occasionally, the fast wave overlapped the stimulus artifact because of the small separation between stimulating and recording electrodes. However, when the stimulating electrode was moved off the preparation, the fast wave disappeared while the stimulus artifact persisted. Reversing the polarity of the leads on the stimulating electrode inverted the artifact but did not invert the fast wave.

On $E 13$, repetitive stimulation at a relatively low rate $(1 / \mathrm{sec})$ had no effect on the fast wave. In contrast, the slow wave became maximally depressed within two trials (Fig. $1 B$ ), and recovery periods of 2 to 5 min were required to restore completely this component of the response. It was difficult to explore further the basis of the response because preparations of this age were often damaged by the suction electrodes. However, the responses seen on E13 closely correspond in their latency and lability to the responses of more mature ganglia.

One day later in fetal development the superior cervical ganglion is more substantial, and its physiology was more easily examined (Fig. $1 C$ ). The response on E14 was similar to that seen on E13: a single stimulus evoked a short-latency, short-duration signal followed by a longer and more irregular response that returned slowly to base line. Relative to the fast wave, the slow wave on E14 was more prominent than on E13. However, the slow wave was still depressed almost completely at a stimulus repetition rate of $1 / \mathrm{sec}$, whereas the fast wave was unchanged. As on E13, several minutes were needed to restore the slow wave to its original size.

To examine the difference between the fast and slow waves, ganglia on E14 were treated with synaptic blocking agents. As a general test for the presence of chemical transmission, the ratio of divalent cations in the bath was altered (Fig. $2 A$ ). This procedure dramatically changed the behavior of the E14 preparation: the same

depresses continuously, whereas the fast wave is not altered. Calibrations apply to $A, B$, and $C$. Note that comparisons of absolute amplitudes in different experiments may not be justified ("Materials and Methods"). 


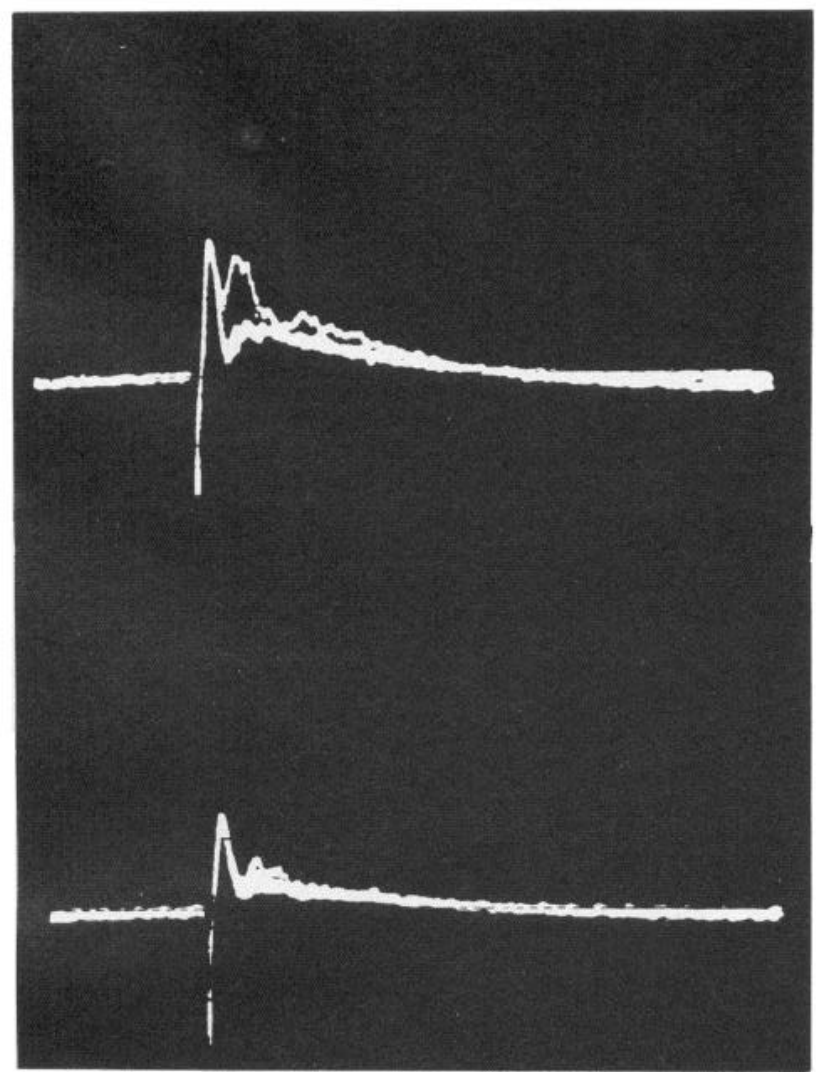

A

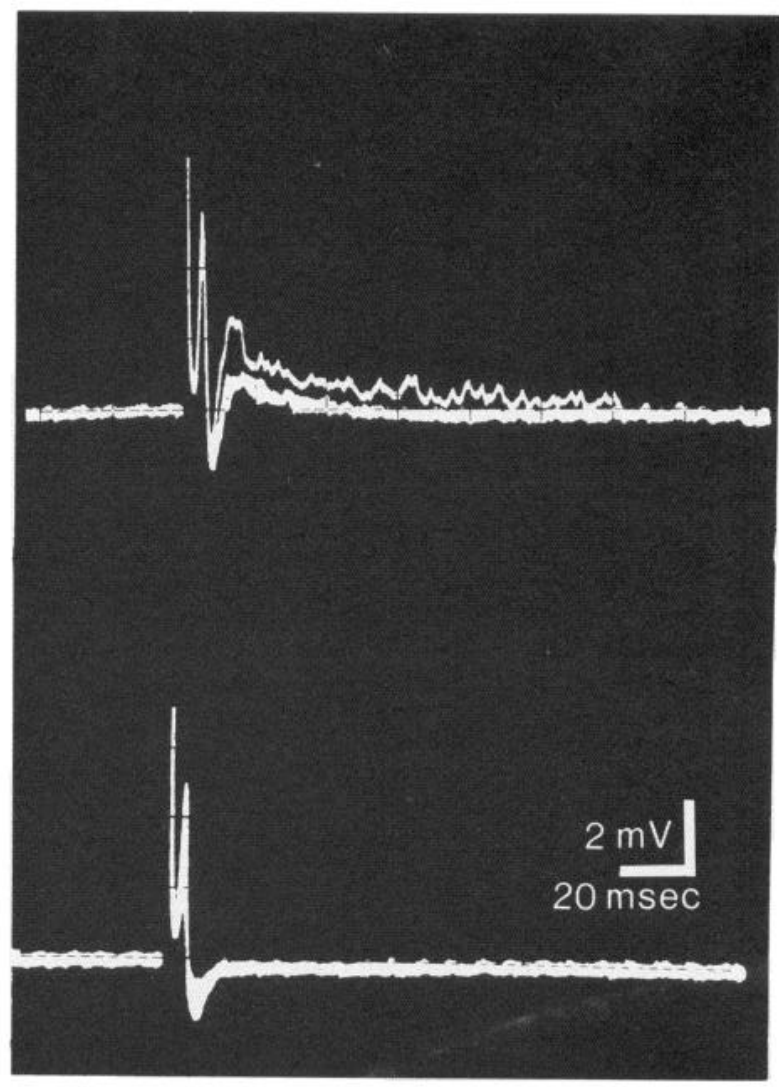

B

Figure 2. Evidence that the slow component of the postganglionic response is synaptically mediated. Recording conditions are as in Figure 1, with a

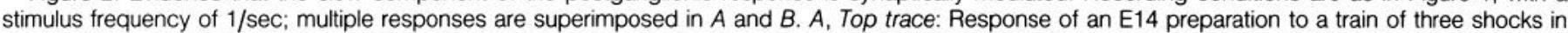

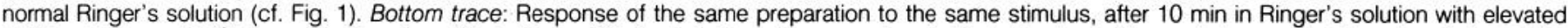

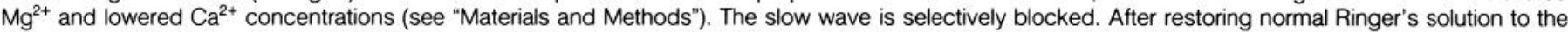

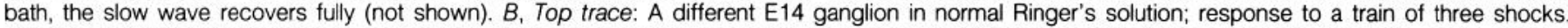

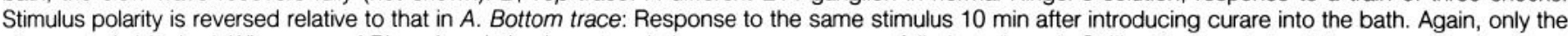
slow wave is blocked. When normal Ringer's solution is restored, the response recovers fully (not shown). Calibrations apply to all traces.

stimulus that evoked both fast and slow waves in standard Ringer's solution evoked primarily the fast wave after a 10-min exposure to high $\mathrm{Mg}^{2+} /$ low $\mathrm{Ca}^{2+}$ Ringer's solution. The form and latency of the fast wave were unchanged. When standard Ringer's solution was restored to the bath, the slow response recovered fully over several minutes.

To determine more specifically the nature of the slow response, a cholinergic blocker was applied to the ganglion (Fig. 2B). After switching from standard saline to a curare solution, the slow wave disappeared, whereas the fast wave remained unchanged. Restoration of standard Ringer's solution led gradually to full recovery of the slow wave.

Throughout prenatal development, separate fast and slow waves were distinguishable by all of the above criteria. However, later in gestation the slow wave took on a smoother, biphasic form, became progressively resistant to fatigue, and grew in amplitude relative to the fast wave (Fig. 3). The form of the postganglionic response seen at birth resembled that seen in the adult (Perri et al., 1970).

Thus, in the developing ganglion, the long-latency response to preganglionic stimulation is particularly labile. Repetitive stimulation, high $\mathrm{Mg}^{2+}$ /low $\mathrm{Ca}^{2+}$, and curare all reversibly block the slow wave. In contrast, the fast wave resists such depression. The simplest explanation of these findings is that the slow wave is mediated by a cholinergic synaptic mechanism, whereas the fast wave represents activation of fibers in the cervical sympathetic trunk that pass completely through the ganglion.

Segmental innervation of the developing superior cervical gan- glion. To study the origin of the ganglion's early innervation, single ventral roots were stimulated, thus activating the preganglionic supply in segmental fractions. On E14, stimulation of each of the ventral roots $\mathrm{C} 8$ to $\mathrm{T} 4$ was effective in evoking a postganglionic response in the internal carotid nerve. The size of the response elicited by the different roots in any single preparation varied in a regular way across these segments (Fig. 4). The postganglionic response evoked by stimulating ventral root $\mathrm{C} 8$ was small; the response grew to a maximum for $\mathrm{T} 1$ or $\mathrm{T} 2$, and then decreased progressively in more caudal segments (T3 and T4). On E14 some animals lacked responses from segment $\mathrm{T} 4$, but the general change in the magnitude of the postganglionic response with segmental level was still apparent. The same pattern was seen in neonatal animals (not illustrated), although by this age, T4 responses appeared consistently, and small responses were also elicited by stimulating ventral root T5.

These findings show that, as early as E14, the strength of innervation contributed by each segment to the superior cervical ganglion varies along the rostrocaudal axis in the same manner as in adult animals (Njå and Purves, 1977a; J. W. Lichtman, unpublished observation). Furthermore, the pattern of innervation described here corresponds to the segmental distribution of the preganglionic supply determined anatomically on E14 and at birth (Rubin, 1985b), as well as in maturity (Rando et al., 1981). Therefore, both anatomical and physiological results show that the innervation of the developing ganglion arises only from appropriate spinal segments.

The morphological development of ganglionic synapses. The 

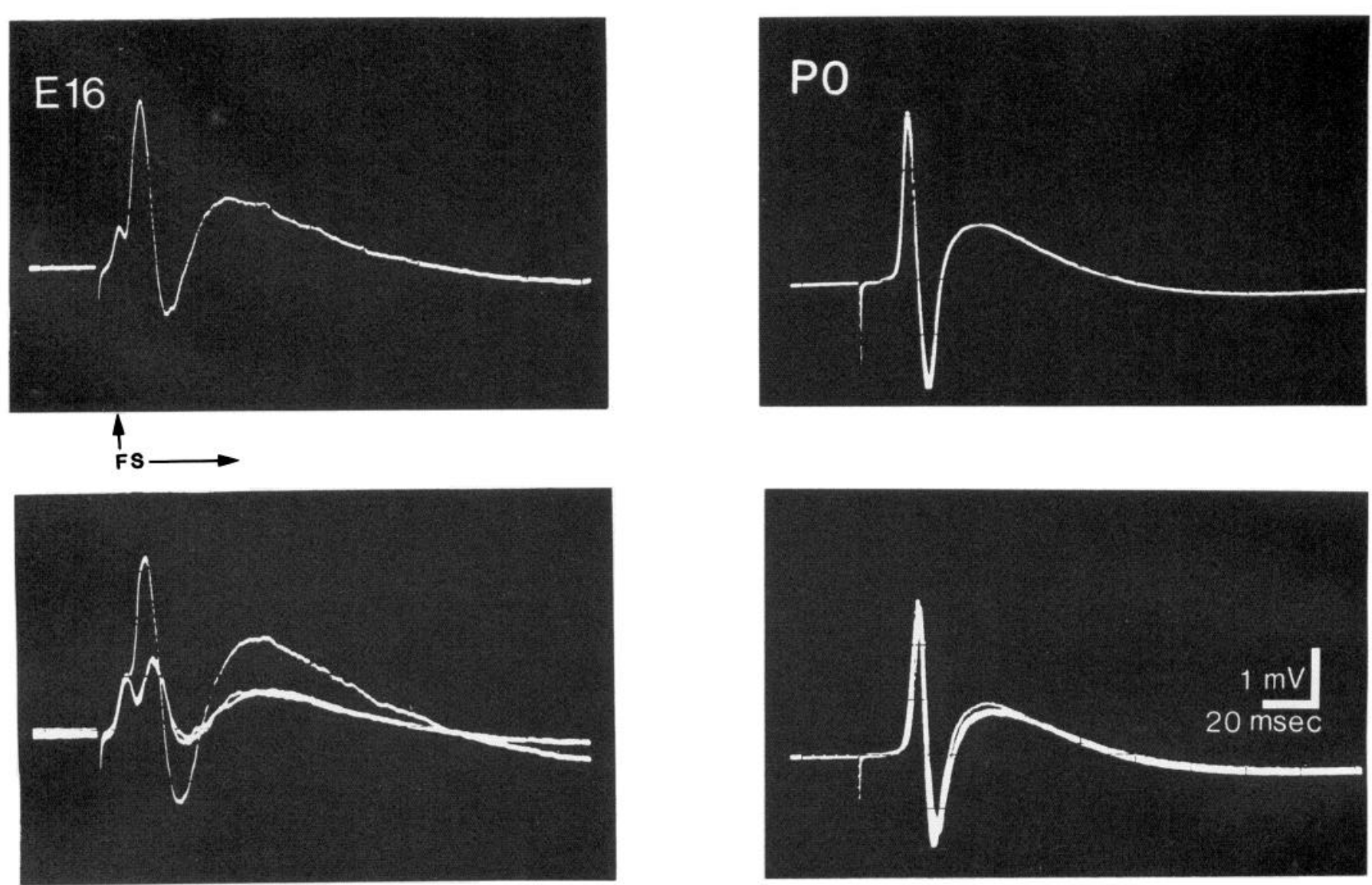

A

B

Figure 3. Further development of the postganglionic response. Recording conditions are as in previous figures. A, Top trace: Response on E16 after a single shock. The slow wave is more coherent than on E14 (Fig. 1) and has become biphasic. The slow response has also greatly increased in amplitude relative to the fast wave, and it obscures the falling portion of the fast wave. Bottom trace: Same preparation; three consecutive shocks at $1 / \mathrm{sec}$. The fast wave becomes more apparent as the slow wave depresses. On E16, however, the slow wave depresses less at $1 /$ sec than on E13 or E14 and stabilizes after the second trial (cf. Fig. 1). B, A series parallel to that in $A$, carried out on P0 (first postnatal day). The biphasic slow wave now dominates the postganglionic response; at the sweep speed used here, the fast wave is lost in the initial upstroke of the slow wave (cf. $A$, top trace). In addition, the slow wave at birth largely resists fatigue during repetitive stimulation at $1 / \mathrm{sec}$ (bottom trace). On both E16 and P0, the slow wave could be selectively depressed by curare or altered $\mathrm{Ca}^{2+} / \mathrm{Mg}^{2+}$ (not illustrated), uncovering the fast wave. Calibrations apply to all traces.

experiments described above indicate that preganglionic axons form connections in the superior cervical ganglion as early as E13; yet at this age no ultrastructural evidence of synapse formation could be found. Synapses could first be detected morphologically on E14, located on both the somata and dendrites of ganglion cells. Junctions at this age contain very small numbers of round clear vesicles apposed to a rudimentary membrane density (Fig. $5, A$ and $B$ ). One day later (E15), better developed synapses are present, characterized by larger numbers of clear vesicles apposed to the presynaptic membrane, a uniform synaptic cleft, and a postsynaptic membrane density symmetrical to that found presynaptically (Fig. 5, C and D). Some of the junctions seen on E15 arise en passant from preganglionic axon shafts, whereas others involve presynaptic elements that are many times wider than ordinary preganglionic axons (see "Discussion").

The overall number of morphologically detectable connections increases substantially before birth (Fig. 6). At the same time, there is a change in the distribution of these connections. Synapses present on E13 occur predominantly on somata: although these synapses cannot be detected in the electron microscope, physiological evidence (Fig. 1) indicates that they develop before ganglion cells acquire dendrites (Rubin, 1985a). Dendrites first appear on E14 and rapidly accept synaptic contacts (Fig. 5B). The number of dendritic contacts soon equals and then exceeds the number of somatic contacts (Fig. 7). The number of somatic contacts counted per cell perimeter shows no consistent change after E15, whereas the number of dendritic contacts increases continuously. At birth, most contacts $(85 \%)$ occur on dendrites. Thus, as synapses proliferate, they are increasingly focused upon the dendrites of target cells.

\section{Discussion}

The onset of innervation in the superior cervical ganglion. A rudimentary ganglionic response to electrical stimulation appears on E13 and, by E14, has developed considerably. The fast and slow components of the response are differentially sensitive to repetitive stimulation, changes in the concentration of divalent cations, and curare. The lability of the slow wave under these conditions, as well as its latency, indicates that it is mediated by cholinergic synapses. On the other hand, the fast wave appears to propagate by a nonsynaptic mechanism. Some postganglionic fibers from the stellate ganglion pass through the cervical sympathetic trunk and traverse the superior cervical ganglion, but these fibers do not emerge in the internal carotid nerve (Bowers and Zigmond, 1981); thus, they probably do not carry the fast wave seen in this study. A more likely pathway for the fast wave exists in those preganglionic axons that innervate superior cervical ganglion cells and then pass into postganglionic nerves (Perri et al., 1970; Purves, 1975). These 

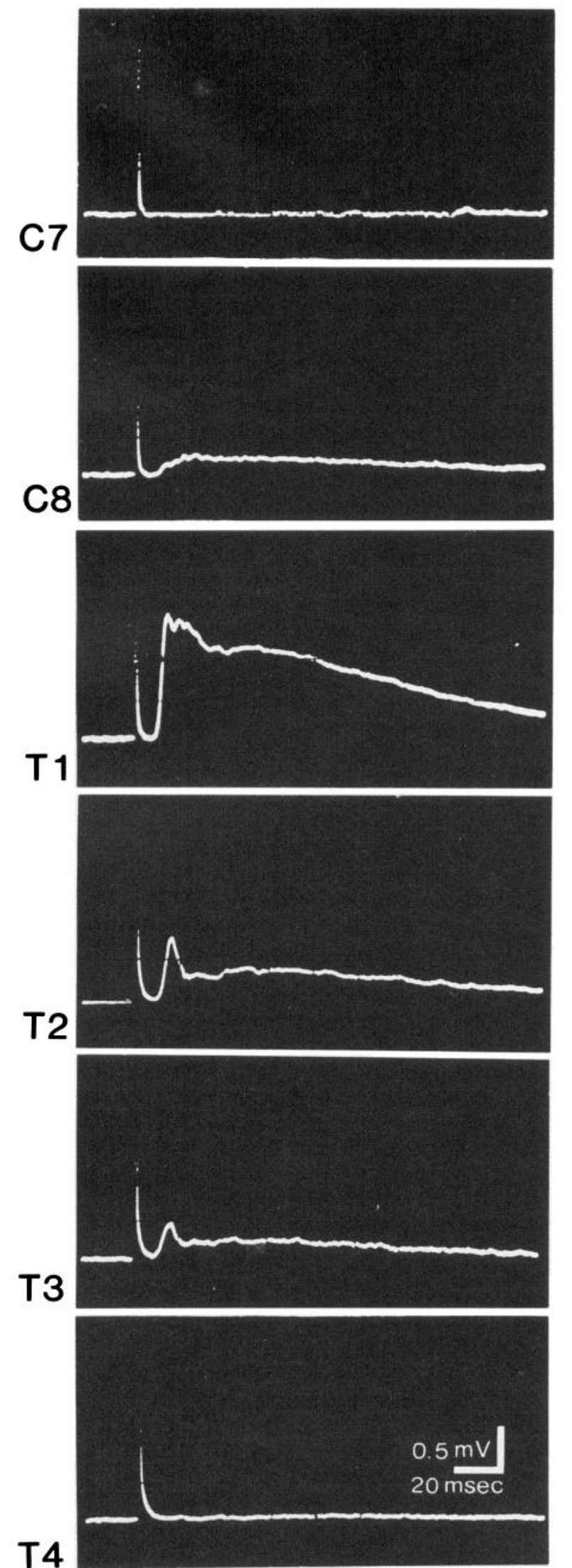

Figure 4. Segmental innervation of the superior cervical ganglion on E14. Each pane/ shows the postganglionic response in the internal carotid nerve following stimulation of the designated ventral root, in a single preparation. The size of the response varies systematically with the level of stimulation. On E14, responses from T4 may be very small or, as in the case shown through-fibers reach the internal carotid nerve at least as early as E14 (Rubin, 1985b).

Since preganglionic axons first enter the superior cervical ganglion around E13 (Rubin, 1985b), it is evident that synapses form without appreciable delay (Fig. 1; see also Landmesser and Pilar, 1972; Kullberg et al., 1977; Dennis et al., 1981). Indeed, some presynaptic elements appear to be axonal growth cones (Fig. 5, C and D; cf. Skoff and Hamburger, 1974), emphasizing the rapidity with which transmission may be established (see Hume et al., 1983; Young and Poo, 1983). When transmission through the ganglion begins, a small proportion of ganglion cells have already left the mitotic cycle and extended their own axons toward postganglionic targets (Rubin, 1985a). The functional relationship between these cells and their peripheral targets is unknown at the time they receive preganglionic innervation; however, during regeneration in the adult, a retrograde influence of target tissues appears necessary for synapse formation in the superior cervical ganglion (Purves and Thompson, 1979).

Further development of ganglionic synapses. During the prenatal period, the through-fiber component of the postganglionic response remains relatively unchanged. The synaptic wave, however, develops dramatically with gestational age, corresponding to morphological changes seen in the ganglion. Synaptic transmission gradually becomes resistant to fatigue at low rates of stimulation (Fig. 3; cf. Landmesser and Pilar, 1972). The increasing stability of the slow wave indicates greater overall efficacy of transmission, consistent with the ultrastructural evidence of synapse proliferation and maturation. By birth, and even on E16, the form of the slow wave resembles that found in the adult.

The rapidity with which newly generated ganglion cells are innervated and the early maturation of the postganglionic response suggest that most ganglion cells receive substantial synaptic input before the end of gestation. This has been confirmed by intracellular recordings from the neonatal rat superior cervical ganglion, which show that each cell receives suprathreshold innervation from several axons (J. W. Lichtman, unpublished results). Similar findings have been reported for the neonatal hamster (Lichtman and Purves, 1980).

In contrast to the present results, studies based on the detection of a synapse-specific enzyme have suggested that significant synaptogenesis begins only in postnatal life (Black et al., 1971). More recently, Smith et al. (1982) similarly concluded that synaptic mechanisms do not develop in the ganglion until some days after birth. Although the number of synapses present at birth is indeed a small fraction of the adult number (Smolen and Raisman, 1980), it is now evident that this relatively sparse innervation is of adequate strength to fire most ganglion cells and already displays many organizational features typical of the adult (see below; Lichtman and Purves, 1980; Rubin, 1985b).

Specificity of connections in the prenatal ganglion. In maturity, subsets of superior cervical ganglion cells supply different portions of the ganglion's overall peripheral territory; cells projecting to any given region are themselves innervated by preganglionic axons from specific subsets of the spinal segments that innervate the ganglion as a whole (Njå and Purves, 1977a; Lichtman et al., 1979). The innervation of adult cells is further organized in that the multiple inputs on a given cell are graded in strength as a function of their spinal level of origin (Njå and Purves, 1977a).

Some aspects of this specificity are apparently set up by very early events in the developing sympathetic system. For example, only appropriate spinal neurons extend presynaptic axons to the superior cervical ganglion (Rubin, 1985b). At the same time, and apparently in a well organized manner, ganglion cells rapidly extend their own axons to peripheral targets (Rubin, 1985a). Although the development of pre- and postganglionic axons and the formation of

here, absent. On P0 (not shown), responses from T4 appear consistently, as well as small responses from T5. These results generally resemble the pattern seen in maturity and match the extent of the preganglionic supply determined anatomically (Rubin, 1985b). Calibrations apply to all panels. 

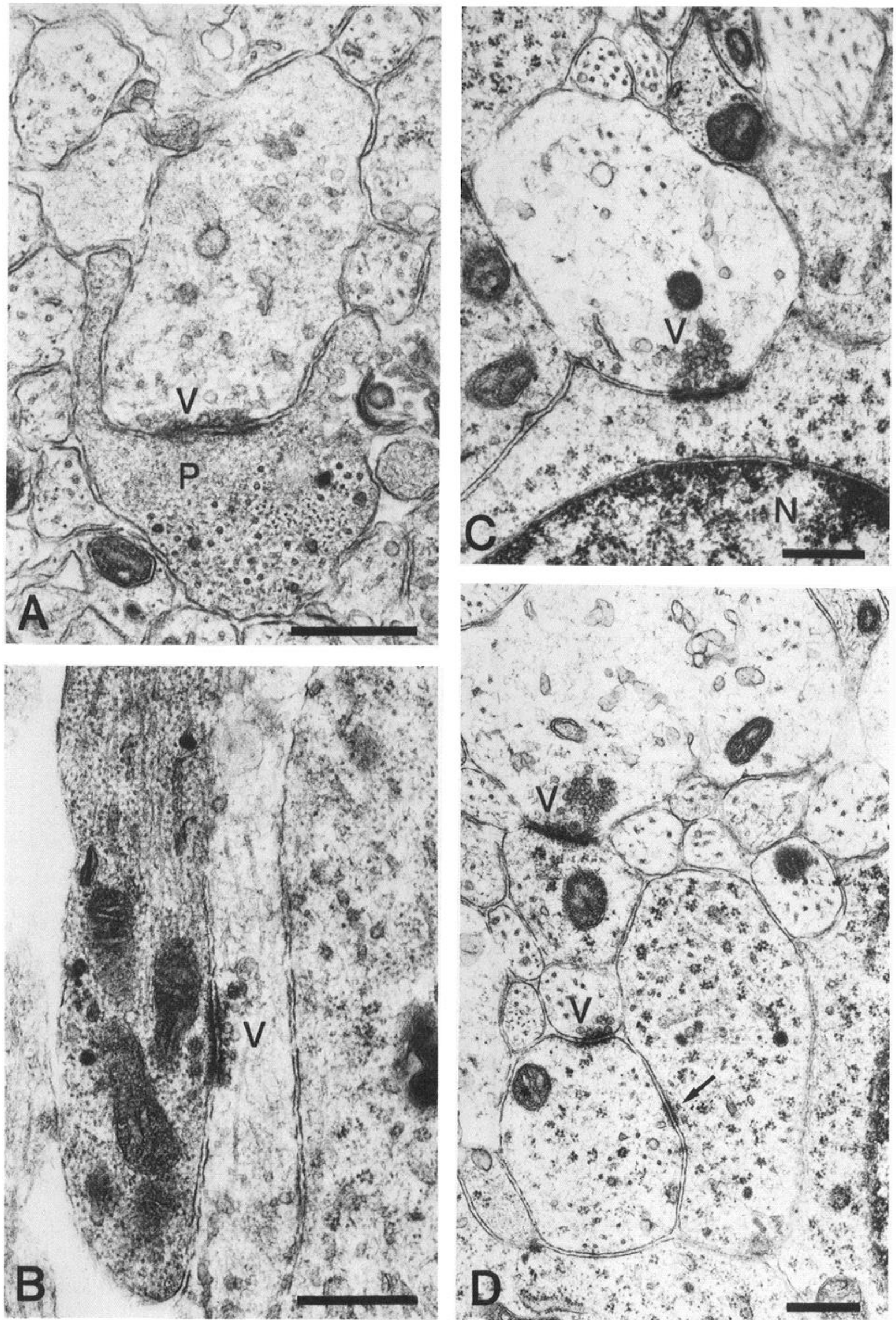

Figure 5. Synaptic junctions in the fetal superior cervical ganglion. Synaptic vesicles $(V)$ are designated in $A$ to $D$. $A$, The earliest morphological evidence of synapse formation (E14); shown here is a rudimentary contact on a process $(P)$ containing somatic organelles. The low number of synaptic vesicles is typical for this age. B, Contact made en passant on a dendrite (E14). C. A somatic contact seen on E15, arising from an expanded preganglionic element (perhaps an axonal growth cone; cf. Skoff and Hamburger, 1974). N, nucleus. D, A similar enlarged contact, impinging on a dendrite (E15). A small en passant contact is seen below it in the field, as well as a nonsynaptic junction (arrow) between two somatic profiles. At early ages, the identification of dendritic synaptic sites was complicated somewhat by the short somatic processes found on developing ganglion cells; by the end of gestation, however, such processes become rare (Rubin, 1985a). Somatic contacts were identified at all ages by the presence of either a nucleus or other somatic organelles in a large postsynaptic profile. Calibration $=0.5 \mu \mathrm{m}$ in $A$ to $D$. 


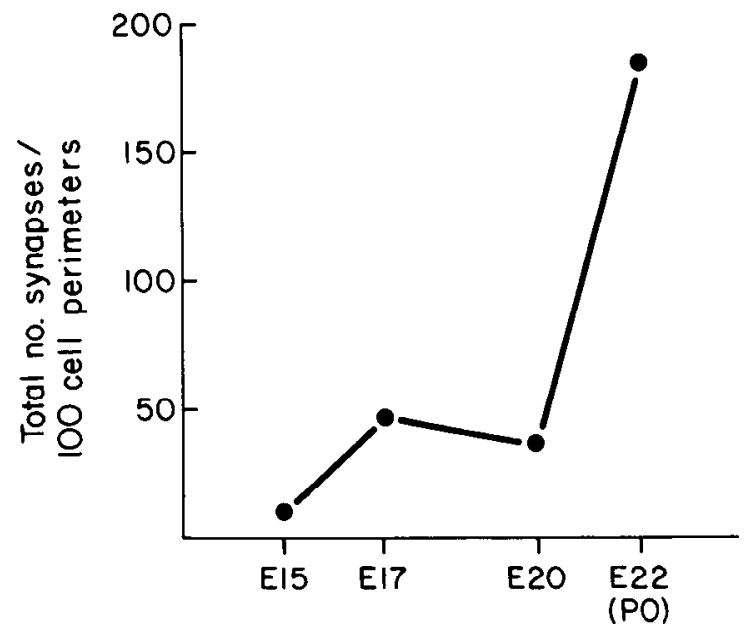

Figure 6. The number of synapses found in sections of the superior cervical ganglion at different ages, normalized to the number of cell perime ters covered during the counting procedure (see "Materials and Methods")

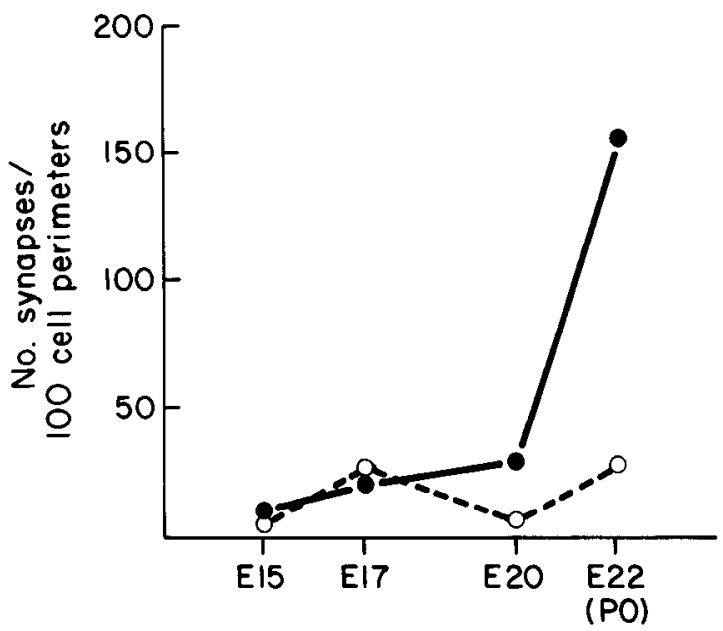

Figure 7. The distribution of synapses on somata and dendrites as a function of age, normalized as in Figure 6. Between E15 and birth (P0), there is no consistent change in the number of somatic contacts $(O)$. Synapses proliferate primarily upon dendrites $(\mathbf{O})$

ganglionic synapses overlap widely in time, it appears that postganglionic axon outgrowth begins at least 1 day before the first presynaptic fibers reach the ganglion (Rubin, 1985a). This makes less probable any mechanism postulating that the destination of a given ganglion cell's axon is determined by the particular preganglionic axons innervating that cell.

In contrast, synaptic specificity may reflect mechanisms whereby preganglionic axons discriminate between different groups of ganglion cells. Such recognition of ganglion cell classes appears to play a role in the development of the chick ciliary ganglion, where distinct neuronal types acquire specific preganglionic inputs from the start (Landmesser and Pilar, 1972, 1974). Similarly, as sympathetic preganglionic axons regenerate in the adult, they rapidly re-form specific connections in a manner that suggests recognition between particular subsets of pre- and postsynaptic cells (Njå and Purves, 1977b, 1978; Purves and Thompson, 1979). The present study indicates that the connections formed during normal sympathetic development also are well organized from the outset and are arranged in a general pattern similar to that seen in the adult. Assuming that the size of the postganglionic response evoked by stimulating a given ventral root reflects the number of ganglion cells innervated by the axons of that root (Njå and Purves, 1977a; J. W. Lichtman, unpublished observation), it appears that even on E14 correct proportions of cells are innervated by axons from different segments. This finding suggests that the initial contacts made by fetal preganglionic axons are largely appropriate (see also Rubin, 1985b) and, as in regeneration, need not undergo extensive adjustment to achieve qualitative accuracy.

Arrangement of synapses on prenatal ganglion cells. There is a gradual quantitative shift during development in the way that preganglionic axons contact individual target cells. On E13, before dendrites develop (Rubin, 1985a), some cells are already innervated. Thus, the initial synapses on sympathetic ganglion cells are presumably axosomatic. The possibility of synapses upon postganglionic axons has not been ruled out, but this seems unlikely since recognizable contacts examined slightly later in development (E14 or E15) occur either on cell somata or on ribosome-containing processes (dendrites or small somatic extensions), rather than on axons. Synapses can first be detected morphologically on E14. This is also the age at which ganglion cells begin to form dendrites (Rubin, 1985a), and on E14 some axodendritic junctions can already be found (Fig. 5). However, on E15, the earliest age at which synaptic sites were quantified, about half of the identifiable contacts are still located on cell bodies, consistent with the idea that the earliest contacts (made around E13) are axosomatic. The number of synapses on cell bodies seems to change little after $E 15$, and eventually dendritic contacts greatly outnumber somatic contacts (Fig. 7; Smolen and Raisman, 1980). Because dendritic growth is asynchronous among ganglion cells (Rubin, 1985a), it is presently impossible to discern in more detail the way in which the site of synapse proliferation is regulated on individual cells.

The change in synaptic distribution during development may be related to the normal quantitative adjustment in which some sympathetic ganglion cells shed redundant initial inputs (Lichtman and Purves, 1980). These phenomena both occur as the overall number of ganglionic synapses increases (Fig. 6; Smolen and Raisman, 1980; see also Lichtman, 1977; Johnson and Purves, 1981). Moreover, both reallocation of synapses and input elimination are tied to the development of dendrites, since the degree of multiple innervation a cell retains apparently is influenced by the geometry of the postsynaptic surface (Hume and Purves, 1981). The development of dendrites is associated with increasing spatial separation of different inputs and perhaps serves to reduce competition between the terminals of axons sharing a given target cell (Forehand and Purves, 1984). The shift of synaptogenesis towards dendrites may well reflect the early stages of this process.

\section{References}

Black, I. B., I. A. Hendry, and L. L. Iversen (1971) Trans-synaptic regulation of growth and development of adrenergic neurones in a mouse sympathetic ganglion. Brain Res 34: 299-240.

Bowers, C. W., and R. E. Zigmond (1981) Sympathetic neurons in lower cervical ganglia send axons through the superior cervical ganglion. Neuroscience 6: 1788-1791.

Dennis, M. J., L. Ziskind-Conhaim, and A. J. Harris (1981) Development of neuromuscular junctions in rat embryos. Dev. Biol. 81: 266-279.

Forehand, C. J., and D. Purves (1984) Regional innervation of rabbit ciliary ganglion cells by the terminals of preganglionic axons. J Neurosci. 4: 112.

Hume, R. I., and D. Purves (1981) Geometry of neonatal neurones and the regulation of synapse elimination. Nature 293: 469-471.

Hume, R. I., L. W. Role, and G. D. Fischbach (1983) Acetylcholine release from growth cones detected with patches of acetylcholine receptor-rich membranes. Nature 305: 632-634.

Johnson, D. A. and D. Purves (1981) Post-natal reduction of neural unit size in the rabbit ciliary ganglion. J. Physiol. (Lond.) 318: 143-159.

Kullberg, R. W., T. L. Lentz, and M. W. Cohen (1977) Development of the myotomal neuromuscular junction in Xenopus laevis: An electrophysiological and fine-structural study. Dev. Biol. 60: 101-129.

Landmesser, L., and G. Pilar (1972) The onset and development of transmission in the chick ciliary ganglion. J. Physiol. (Lond.) 222: 691-713.

Landmesser, L., and G. Pilar (1974) Synapse formation during embryogenesis on ganglion cells lacking a periphery. J. Physiol. (Lond.) 241: 715736. 
Lichtman, J. W. (1977) The reorganization of synaptic connexions in the rat submandibular ganglion during post-natal development. J. Physiol. (Lond.) 273: $155-177$.

Lichtrnan, J. W., and D. Purves (1980) The elimination of redundant preganglionic innervation to hamster sympathetic ganglion cells in early post-natal life. J. Physiol. (Lond.) 301: 213-228.

Lichtman, J. W., D. Purves, and J. W. Yip (1979) On the purpose of selective innervation of guinea-pig superior cervical ganglion cells. J. Physiol. (Lond.) 292: 69-84.

Njå, A., and D. Purves (1977a) Specific innervation of guinea-pig superior cervical ganglion cells by preganglionic fibres arising from different levels of the spinal cord. J. Physiol. (Lond.) 264: 565-583.

Njå, A., and D. Purves (1977b) Re-innervation of guinea-pig superior cervical ganglion cells by preganglionic fibres arising from different levels of the spinal cord. J. Physiol. (Lond.) 272: 633-651.

Njä, A., and D. Purves (1978) Specificity of initial synaptic contacts made on guinea-pig superior cervical ganglion cells during regeneration of the cervical sympathetic trunk. J. Physiol. (Lond.) 281: 45-62.

Perri, V., O. Sacchi, and C. Casella (1970) Synaptically mediated potentials elicited by the stimulation of post-ganglionic trunks in the guinea-pig superior cervical ganglion. Pflugers Arch. 314: 55-67.

Purves, D. (1975) Functional and structural changes in mammalian sympathetic neurones following interruption of their axons. J. Physiol. (Lond.) 252: $429-463$
Purves, D., and W. Thompson (1979) The effects of post-ganglionic axotomy on selective synaptic connexions in the superior cervical ganglion of the guinea-pig. J. Physiol. (Lond.) 297: 95-110.

Rando, T. A., C. W. Bowers, and R. E. Zigmond (1981) Localization of neurons in the rat spinal cord which project to the superior cervical ganglion. J. Comp. Neurol. 196: 73-83.

Rubin, E. (1982) Embryonic development of the rat superior cervical ganglion. Soc. Neurosci. Abstr. 8: 6.

Rubin, E. (1985a) Development of the rat superior cervical ganglion: Ganglion cell maturation. J. Neurosci. 5: 673-684.

Rubin, E. (1985b) Development of the rat superior cervical ganglion: Ingrowth of preganglionic axons. J. Neurosci. 5: 685-696.

Skoff, R. P., and V. Hamburger (1974) Fine structure of axonal and dendritic growth cones in embryonic chick spinal cord. J. Comp. Neurol. 153: 107148.

Smith, P. G., T. A. Slotkin, and E. Mills (1982) Development of sympathetic ganglion neurotransmission in the neonatal rat. Pre- and postganglionic nerve response to asphyxia and 2-deoxyglucose. Neuroscience 7: 501507.

Smolen, A., and G. Raisman (1980) Synapse formation in the rat superior cervical ganglion during normal development and after neonatal deafferentation. Brain Res. 181: 315-323.

Young, S. H., and M. -M. Poo (1983) Spontaneous release of transmitter from growth cones of embryonic neurones. Nature 305: 634-637. 